\title{
Tsafon
}

Revue d'études juives du Nord

$78 \mid 2019$

L'antijudaïsme dans l'Antiquité

\section{Généalo-J, Revue française de généalogie}

\section{Danielle Delmaire}

\section{(2) OpenEdition}

Journals

Édition électronique

URL : https://journals.openedition.org/tsafon/2697

DOI : $10.4000 /$ tsafon.2697

ISSN : 2609-6420

\section{Éditeur}

Association Jean-Marie Delmaire

\section{Édition imprimée}

Date de publication : 1 décembre 2019

Pagination : 192-193

ISSN : 1149-6630

\section{Référence électronique}

Danielle Delmaire, « Généalo-J, Revue française de généalogie », Tsafon [En ligne], 78| 2019, mis en ligne le 01 décembre 2019, consulté le 29 juin 2021. URL : http://journals.openedition.org/tsafon/2697 ; DOI : https://doi.org/10.4000/tsafon.2697

Ce document a été généré automatiquement le 29 juin 2021.

Tsafon. Revues d'études juives du Nord 


\title{
Généalo-J, Revue française de généalogie
}

\author{
Danielle Delmaire
}

\section{RÉFÉRENCE}

$$
\mathrm{n}^{\circ} 137,55 \mathrm{p} \text {. }
$$

1 La revue du Cercle de Généalogie Juive n'est pas un simple bulletin d'informations diffusé entre généalogistes amateurs. Ses contributeurs donnent toujours à lire, à travers des parcours individuels ou familiaux, des articles qui rendent compte de l'histoire des familles juives, ou/et de communautés, et qui nourrissent les connaissances sur l'histoire des juifs en général. Le dernier numéro en est la preuve.

2 L'historien des communautés juives d'Algérie, Jean Laloum, étudie les «persécutions et déportations [des] Juifs natifs du Constantinois dans la France de Vichy ». Les juifs d'Algérie ne furent pas déportés, néanmoins certains d'entre eux ont connu l'extrême rigueur des camps du sud du pays, mais des noms de juifs originaires d'Algérie figurent sur les listes de déportés car quelques familles s'étaient installées en France métropolitaine avant la guerre et notamment à Marseille où la grande rafle du 22 au 24 janvier 1943 décime la communauté juive. À partir de cas particuliers exhumés de sources archivistiques, l'auteur évoque des parcours semblables et différents à la fois. Deux jeunes gens " maris d'aryenne ", deux familles, une vendeuse des quatre saisons sont raflés, parfois sur dénonciation! Le point commun de ces familles : les conjoints « aryens » ou les enfants de « mère aryenne » sont épargnés. Voilà une étude qui dépasse un simple exposé de généalogiste.

3 Même remarque pour l'« Histoire et mémoire de Fortunée Abignoli » racontée par son arrière-petit-fils, Julien Colet. Le souvenir de Fortunée reste bien flou parmi ses descendants et son arrière-petit-fils dut avoir recours à des archives pour compléter les maigres renseignements que pouvaient lui fournir les membres de sa famille. Il en conclut, à regret, un désir partagé d'oublier les moments douloureux de la guerre, ce 
qui finit par jeter aux oubliettes un pan de l'histoire familiale et de l'histoire des juifs plus généralement. Car le parcours de Fortunée est original mais fréquent à la fois. Née en Égypte, elle n'y resta pas et s'installa à Marseille après son mariage avec un juif deux fois veufs et déjà père. Elle assuma l'éducation de toute cette fratrie alors qu'elle-même devint prématurément veuve. Elle y gagna en indépendance et en autonomie. Elle ne parvint pas à se convaincre du danger et elle fut arrêtée puis emportée vers Auschwitz par le convoi 52. Sa fille Laure, la grand-mère de l'auteur, perdit sa mère, un frère et un compagnon, père de son bébé, qu'elle déclara de mère inconnue pour lui épargner la déportation. Trop de meurtrissures accablaient Laure qui " a transmis à ses filles la souffrance de la Shoah et de la guerre mais non la connaissance » et, plus douloureux encore, «près de cinquante ans après la Shoah, liens familiaux et religieux étaient brisés » regrette son petit-fils.

De même encore, le récit d'Andrée Margolin, « Une jeune fille juive sous l'Occupation (1940-1944) » publié grâce à son fils, témoigne de la volonté d'une étudiante brillante de mener à leur terme ses études. Le récit débute à Paris aux premiers mois de l'Occupation, le père averti et prudent - il a eu connaissance de l'appel du général de Gaulle - est néanmoins arrêté puis interné à Drancy. Ironie tragique : c'est là qu'il reçoit son diplôme d'officier pour services rendus à la France !!! C'est peut-être ce qui lui permet d'être libéré. Commence alors une vie plus errante mais jamais vraiment cachée. Des amis, des voisins, des employeurs les aident et la jeune Andrée parvient coûte que coûte à passer ses examens même si son entrée à l'École Normale Supérieure n'est pas homologuée comme ce fut le cas de tous les candidats juifs. Malgré ses réussites, Andrée constate : " J'ai gardé la vie, j'ai fait mes études presque normalement mais on m'a volé ma jeunesse : je n'ai jamais eu dix-huit ans ».

Plus généalogiste est la contribution d'Anne-Marie Fribourg qui raconte " Une saga américaine : la descendance de Victor Fribourg (Niederwisse, Moselle, 10 janvier 1797 New York, 7 mai 1884) soldat de l'Empereur et par laquelle on suit brièvement le parcours de chacun de ses neufs enfants et leurs descendants, établis pour la plupart aux USA.

Enfin Éliane Roos-Schul, érudite en épigraphie juive, livre la lecture et l'interprétation d'un « sceau à l'arbre accosté d'oiseaux de Menahem Ezobi » des XVe-XVIe siècles. 